\title{
Methane production in different breeds, grazing different pastures or fed a total mixed ration, as measured by a Laser Methane Detector
}

\author{
S.M. Grobler ${ }^{1,2 \#}$, M.M. Scholtz ${ }^{2,3}$, H. van Rooyen ${ }^{1}$, M. Mpayipheli ${ }^{1}$ \& F.W.C. Neser ${ }^{2}$ \\ ${ }^{1}$ Agricultural Research Council, Private Bag X05, Lynn East 0039, South Africa; ${ }^{2}$ University of the Free State, P.O. Box \\ 339, Bloemfontein 9300, South Africa; ARC-Animal Production Institute, Private Bag X2, Irene 0062, South Africa
}

(Received 4 January 2014; Accepted 5 June 2014; First published online 22 August 2014)

\author{
Copyright resides with the authors in terms of the Creative Commons Attribution 2.5 South African Licence. \\ See: http://creativecommons.org/licenses/by/2.5/za \\ Condition of use: The user may copy, distribute, transmit and adapt the work, but must recognise the authors and the South African \\ Journal of Animal Science.
}

\begin{abstract}
Agriculture is responsible for $5 \%$ to $10 \%$ of the global anthropogenic greenhouse gas (GHG) emissions. Livestock contribute about $65 \%$ of agricultural GHG and enteric fermentation accounts for $90 \%$ of this. The global warming potential of $\mathrm{CH}_{4}$ is known to be 23 times more than that of carbon dioxide, resulting in it being a significant role player in the greenhouse gas family. The laser methane detector (LMD) is an instrument that has the potential to measure enteric $\mathrm{CH}_{4}$ emission from livestock under normal husbandry activities. This study was aimed at evaluating the efficiency and results, when using the LMD to measure $\mathrm{CH}_{4}$ production under normal production conditions. Twelve heifers, four each from the Bonsmara, Nguni and Jersey breeds, were subjected to grazing natural veld, forage sorghum under irrigation, oats pasture under irrigation or a total mixed ration. Measurements were taken late afternoon (18:00) when the animals were ruminating. Four repeated measurements, lasting 60 seconds each, were taken on 10 consecutive days on each of the production systems. The animals were adapted for a period of 14 days on the specific feed, before the measurements were taken. The Jersey heifers produced significantly less $\mathrm{CH}_{4}$ than the Bonsmara and Nguni on natural veld, with no significant differences between breeds on the forage sorghum. On natural veld the heifers generated $48 \%$ more $\mathrm{CH}_{4}$. These results thus indicate that the LMD produce sensible and repeatable measurements that can be interpreted in respect of $\mathrm{CH}_{4}$ production by cattle. The next step will be to increase the number of breeds, numbers per breed, and feeding strategies over all seasons in order to validate and build up a baseline data set on the use of the LMD to measure $\mathrm{CH}_{4}$ emissions from cattle under different grazing conditions.
\end{abstract}

Keywords: Heifers, methane emission, pastures, total mixed ration

\# Corresponding author: mgrobler@arc.agric.za

\section{Introduction}

Agriculture is responsible for $5 \%$ to $10 \%$ of the global anthropogenic greenhouse gas (GHG) emissions. Livestock contributes about $65 \%$ of agricultural GHG, and enteric fermentation accounts for $90 \%$ of this (Meissner et al., 2012). The global warming potential of methane is 23 times more than that of carbon dioxide $\left(\mathrm{CO}_{2}\right)$, resulting in it being a significant role player in greenhouse gas production (Scholtz et al., 2013). Methane, as part of the GHG family, can affect the climate directly through its interaction with longwave infra-red energy and indirectly through atmospheric oxidation reactions that produce $\mathrm{CO}_{2}$, a potent GHG. More recently, attention has been given to $\mathrm{CH}_{4}$ 's potential contribution to climatic change and global warming (Johnson \& Johnson, 1995).

Enteric methane production is a by-product of ruminant anaerobic fermentation in the rumen and large intestine by microbes in a process called methanogenesis or biomethanation. The animals then release the methane into the atmosphere mainly by exhaling the gas through the mouth and nostrils. Enteric methane produced by cattle can thus be seen as a loss of feed energy from the diet and reflects the inefficient utilization of the feed (Wood \& Knipmeyer, 1998). The production rate of enteric methane can vary, depending on the digestive system and level of feed intake of the individual animals, as well as type of carbohydrate in the diet, feed processing, addition of lipids or ionophores to the diet, alterations in the ruminal microflora and different animal activities (Chagunda, 2013).

The need for accurate estimates of enteric methane production in ruminants in different systems has been emphasized in a number of reports. Understanding the differences in enteric methane production from 
ruminants in different production systems is important for developing mitigation strategies for the contribution of agricultural activities to the anthropogenic methane emission (Chagunda et al., 2009). Current methods to measure $\mathrm{CH}_{4}$ emissions from livestock include the use of respiration calorimetry chambers (Kelly et al., 1994; Murray et al., 1999), which provide accurate measures of methane emissions for limited numbers of animals under controlled conditions, but are impractical for use in a farm environment (Garnsworthy et al., 2012). Tracer techniques (Johnson et al., 1994; McGinn et al., 2006), which are used under semicommercial conditions, require a gas collection apparatus attached to the cow, insertion of rumen boluses to release SF6, and frequent cow handling, which generally interfere with the cow's behaviour (Johnston et al., 1994). Mass balance/micro-meteorological techniques, which range from the use of aircraft to sample methane concentrations at different levels in the atmosphere to paddock scale applications as well as prediction equations, have also been developed (Judd et al., 1999; Lassey et al., 2000; Laubach et al., 2008; Teeranavattanakul, 2010). Therefore, researchers identified a need for an inexpensive, convenient and practical method of quantifying the amount of enteric methane produced by ruminants.

The use of a recently-developed, proprietary, laser methane detector (LMD) in dairy cows was first initiated and explored by Chagunda et al. (2009). The LMD is a hand-held gas detector for the remote measurements of the column density for methane containing gases (Tokyo Gas Engineering). The LMD instrument is based on infrared absorption spectroscopy, using a semi-conductor laser, as a collimated excitation source and employing a second harmonic detection of wavelength modulation spectroscopy to establish a methane concentration measurement.

The integrated concentration of methane between the equipment and the target point is then digitally displayed. The measured value is expressed as methane concentration, while taking into account the thickness of any methane plume. Hence, the measurements are expressed in parts per million-meter (ppm$\mathrm{m}$ ). The instrument normally operates in a temperature range of between 0 and $40^{\circ} \mathrm{C}$ and in humidity range of 20\% - 90\% (Chagunda et al., 2009). The LMD has subsequently been used extensively in detection applications, such as gas transmission networks, landfill sites and other areas where methane leakage or build-up is a risk (Crowcon, 2006).

Chagunda \& Yan (2011) tested the degree of accuracy between the LMD and the indirect open-circuit respiration calorimetric chamber. The test was based on two different methods, i.e. Pearson correlation and an analysis of agreement based on the Bland and Altman methodology. The correlation coefficient of the LMD and the calorimeter chamber was high $(r=0.8)$ and positive. The Bland and Altman methodology demonstrated high levels of correlation between measurements of the LMD and the calorimeter chamber. Furthermore, inverse regressions provided sufficiently close estimates of the chamber measurements, based on the LMD readings (Chagunda \& Yan, 2011).

Previous studies have concentrated solely on testing the LMD under indoor conditions, while Teeranavattanakul (2010) reported the effect of different environmental factors on the LMD measurements performed under outdoor conditions. Taking into account all the environmental factors investigated by Teeranavattanakul (2010), the current study was aimed at examining the laser methane detector, under normal natural cattle feeding conditions.

\section{Materials and methods}

Twelve heifers, four each of the Bonsmara, Nguni and Jersey breeds, grazing on natural sour veld, forage sorghum under irrigation, oats pasture under irrigation or fed a total mixed ration (TMR), were used and measurements were taken late afternoon (18:00), when the animals were ruminating. Measurements were taken on individual animals with a minimum radius of $3 \mathrm{~m}$ from any other animal. Gas column density, at a distance of $3 \mathrm{~m}$ from the animal, was measured by directing the auxiliary LMD targeting laser beam at the nostrils of the heifer. The $3 \mathrm{~m}$ distance was used to be able to measure methane production from the animal, without creating a situation where the animal's activity was disturbed (Gibbons et al., 2009). The animals were adapted for 14 days on the specific grazing or feed before the measurements were taken. All measurements were taken at the same time of the day (18:00) as it proved to be difficult to see the laser beam in direct sunlight and no or very little wind was experienced at this time of day. The measurements for each individual heifer were then taken every 5 seconds over a period of 60 seconds, to include the different stages of the tidal respiratory cycle. Four 60 second repeated measurements were taken on 10 consecutive days on each of the grazing or feeding conditions. Enteric methane production is normally reported per day or per unit of product produced; however, in the current study, enteric methane was expressed in ppm-m. One of the aims of this study was to evaluate the recording of measurements under applied farm conditions by using the LMD. Data was analyzed with the application of the Proc GLM of SAS (SAS, 2000). 


\section{Results and Discussion}

The Jersey heifers produced significantly $(P<0.05)$ less methane than the Bonsmara and Nguni heifers on natural veld, as demonstrated in Table 1. No significant difference were recorded between breeds grazing forage sorghum $(P>0.05)$, although the Ngunis showed a tendency to produce more $\mathrm{CH}_{4}$ than the Jersey heifers, especially. As expected, significantly less methane was produced when the animals were grazing on the forage sorghum under irrigation, compared to the natural veld $(P<0.0001)$, possibly due to the tannin content found in forage sorghum. On natural veld the animals produced on average $48 \%$ more methane, compared to grazing forage sorghum. The Bonsmara and Nguni heifers produced slightly less methane on the TMR than on natural veld, but the Jerseys produced more methane on the TMR than on natural veld. The Jerseys produced slightly less methane on the oats pasture than on the total mixed ration, but both the Bonsmara and Nguni heifers produced less methane on the total mixed ration than grazing the oats pasture under irrigation. There may be a possibility that dairy cattle may react differently than beef cattle on different feed sources, e.g. selective grazing by the Jersey heifers on natural veld.

Table 1 The mean $( \pm S D)$ methane production (parts per million per meter) of 12-month-old Jersey, Nguni and Bonsmara heifers utilizing different feed sources

\begin{tabular}{lcccc}
\hline & Natural veld & Total mixed ration & Oats grazing & Forage sorghum \\
\hline Bonsmara & $32.7^{\mathrm{a}, \mathrm{b}} \pm 5.3$ & $31.3^{\mathrm{a}, \mathrm{b}, \mathrm{c}} \pm 9.8$ & $26.3^{\mathrm{c}, \mathrm{d}} \pm 7.3$ & $15.3^{\mathrm{e}} \pm 1.6$ \\
Jersey & $25.8^{\mathrm{c}, \mathrm{d}} \pm 1.1$ & $36.6^{\mathrm{a}} \pm 3.4$ & $30.7^{\mathrm{b}, \mathrm{c}} \pm 7.0$ & $14.5^{\mathrm{e}} \pm 1.7$ \\
Nguni & $30.6^{\mathrm{b}, \mathrm{c}} \pm 1.4$ & $26.4^{\mathrm{c}, \mathrm{d}} \pm 4.0$ & $24.6^{\mathrm{d}} \pm 3.0$ & $16.5^{\mathrm{e}} \pm 2.8$ \\
\hline
\end{tabular}

${ }^{a, b, c, d}$ Means in both rows and columns with different superscripts are significantly different $(P \leq 0.05)$.

There were significant differences between methane production from the different breeds (Table 2), with a slight interaction between breed and feed source, although not significant.

Table 2 Analysis of variance of animal, feed source, breed and feed source/breed interaction

\begin{tabular}{lcccc}
\hline Source & DF & Mean square & F value & Pr $>$ F \\
\hline Animal & 3 & 87.30 & 5.56 & 0.0035 \\
Feed source & 3 & 598.13 & 38.07 & $<.0001$ \\
Breed & 2 & 23.43 & 1.49 & 0.2402 \\
Feed source $x$ breed & 6 & 59.66 & 3.80 & 0.0057 \\
\hline
\end{tabular}

From Table 3 it would seem that the feeding of a TMR produced more methane than in heifers grazing on natural veld, oats or forage sorghum. These results are in contrast with most other studies which show a lower methane production from high quality feed. However, this phenomenon has been recorded in a few unpublished studies and need further investigation.

It would seem as if individual animals have a tendency to emit higher or lower quantities of methane, irrespective of the feed source. This tendency is evident in Table 4, where the Bonsmara heifer number 3 emitted the most methane on 3 feed sources (veld, total mixed ration and oats), whereas the Bonsmara number 4 emitted the least methane on these feed sources, compared to the other Bonsmara heifers in the group. 
Table 3 Mean ( \pm SD) methane production (parts per million per meter) of Jersey, Nguni and Bonsmara heifers on different feed sources

\begin{tabular}{lc}
\hline Feed source & Mean \pm standard deviation \\
\hline Natural veld & $29.70^{\mathrm{a}} \pm 4.23$ \\
Total mixed ration & $31.42^{\mathrm{a}} \pm 7.26$ \\
Oat grazing & $27.20^{\mathrm{b}} \pm 6.12$ \\
Forage sorghum & $15.55^{\mathrm{c}} \pm 2.10$ \\
\hline $\mathrm{a}, \mathrm{b}, \mathrm{c}, \mathrm{d}$ & \\
\hline
\end{tabular}

Table 4 Average methane production (parts per million per meter) measured from four Bonsmara heifers on different feed sources

\begin{tabular}{clccc}
\hline Bonsmara & Natural veld & Total mixed ration & Oats pasture & Forage sorghum \\
\hline 1 & 29.48 & 26.67 & 28.50 & $13.51^{(4)}$ \\
2 & 35.83 & 30.54 & 23.58 & 14.52 \\
3 & $38.53^{(1)}$ & $45.19^{(1)}$ & $35.22^{(1)}$ & 16.25 \\
4 & $27.08^{(4)}$ & $22.75^{(4)}$ & $18.07^{(4)}$ & $17.06^{(1)}$ \\
\hline
\end{tabular}

\footnotetext{
${ }^{(1)}$ Bonsmara heifer with the highest methane emission in the group.
}

(4) Bonsmara heifer with the lowest methane emission in the group.

\section{Conclusion}

From these results it is clear that the LMD produced recordable measurements, which can be interpreted in respect to enteric methane emission in cattle. The next step should be to increase the number of breeds, number of animals per breed, and feeding strategies over all seasons, in order to validate and build a baseline data set, regarding the use of the LMD to measure methane emissions from cattle on different feed sources and grazing conditions.

The possibility of differences in methane production between animals of the same breed indicates that it may be possible to identify genetic differences between animals using the LMD and it is recommended that this be investigated.

\section{Acknowledgements}

This work is based on research supported in part by Red Meat Research and Development South Africa and the National Research Foundation of South Africa (NRF), under grant UID 75123. The Grantholder acknowledges that opinions, findings and conclusions or recommendations expressed in any publication generated by NRF-supported research are that of the authors and that the NRF accepts no liability whatsoever in this regard.

\section{References}

Chagunda, M.G.G., 2013. Opportunities and challenges in the use of the Laser Methane Detector to monitor enteric methane emissions from ruminants. The Animal Consortium 2013 Anim, 7: s2. Published online: 06 June 2013. pp. 392-400.

Chagunda, M.G.G. \& Yan, T., 2011. Do methane measurements from a laser detector and an indirect opencircuit respiration calorimetric chamber agree sufficiently closely? Anim. Feed Sci. Technol. 165, 8-14.

Chagunda, M.G.G., Ross, D. \& Roberts, D.J., 2009. On the use of a Laser Methane Detector in dairy cows. Comput. Electron. Agric. 68, 157-160.

Crowcon Detection Instruments, 2006. New hand held device detects methane up to 150 metres away. http://www.crowcon.com

Garnsworthy, P.C., Craigon, J., Hernandez-Medrano, J.H. \& Saunders, N., 2012. On-farm methane measurements during milking correlate with total methane production by individual dairy cows. J. Dairy Sci. 95, 3166-2180. 
Gibbons, J., Lawrence, A. \& Haskell, M., 2009. Responsiveness of dairy cows to human approach and novel stimuli. Appl. Anim. Behav. Sci. 116, 163-173.

Johnson, K.A. \& Johnson, D.E., 1995. Methane emissions from cattle. J. Anim. Sci. 195. 73, 2483-2492.

Johnson, K., Huyler, M., Westberg, H., Lamb, B. \& Zimmerman, P., 1994. Measurement of methane emissions from ruminant livestock using a sulfur hexafluoride tracer technique. Environ. Sci. Technol. 28, 359-362.

Judd, M.J., Kelliher, F.M., Ulyatt, M.J., Lassey, K.R., Tate, K.R., Shelton, I.D., Harvey, M.J. \& Walker, C.F., 1999. Net methane emissions from grazing sheep. Glob. Change Biol. 5, 647-657.

Kelly, J.M., Kerrigan, L.P., Milligan, L.P. \& McBride, B.W., 1994. Development of a mobile, open circuit indirect calorimetry system. Can. J. Anim. Sci. 74, 65-72.

Lassey, K.R., Gimson, N.R., Wratt, D.S., Brailsford, G.W. \& Bromley, A.M., 2000. Verifying agricultural emissions of methane. Non- $\mathrm{CO}_{2}$ greenhouse gases: Scientific understanding, control and implementation. Ed: Van Ham, J., Kluwer Academic Publishers, Dordrecht. pp.107-114.

Laubach, J., Kelliher, F.M., Knight, T.W., Clark, H., Molano, G. \& Cavanagh, A., 2008. Methane emissions from beef cattle - a comparison of paddock- and animal-scale measurements. Aust. J. Exp. Agr. 48, 132-137.

McGinn, S.M., Beauchemin, K.A., Iwaasa, A.D. \& McAllister, T.A., 2006. Assessment of the sulfur hecafluoride $\left(\mathrm{SF}_{6}\right)$ tracer technique for measuring enteric methane emissions from cattle. J. Environ. Qual. 35, 1686-1691.

Meissner, H.H., Scholtz, M.M. \& Schönfeldt, H.C., 2012. The status, socio-economic and environmental impact, and challenges of livestock agriculture in South Africa. www.rmrdsa.co.za

Murray, P.J., Moss, A., Lockyer, D.R. \& Jarvis, S.C., 1999. A comparison of systems for measuring methane emissions from sheep. J. Agric. Sci. 133, 439-444.

Rutherford, M.C. \& Westfall, R.H., 1994. Biomes of Southern Africa: an objective characterization. Mem. Bot. Surv. S. Afr. No 63.

SAS, 2000. Statistical Analysis Systems user's guide, Version 8.02 ed., SAS Institute Inc., Raleigh, North Carolina, USA.

Scholtz, M.M., Van Ryssen, J.B.J., Meissner, H.H. \& Laker, M.C., 2013. A South African perspective on livestock production in relation to greenhouse gases and water usage. S. Afr. J. Anim. Sci. 43, 247-254.

Teeranavattanakul, P., 2010. Investigation factors affecting Laser Methane Detector measurements under outdoor condition. MSc thesis, University of Glasgow, Scotland.

Wood, D. \& Knipmeyer, C.K., 1998. Global Climate Change and Environmental Stewardship by Ruminant Livestock Producers. National Council for Agricultural Education, University of Missouri, USA. 